\title{
Retos de la política de ayuda humanitaria de la Unión Europea: entre la coherencia y la independencia
}

\section{Enriqueta Serrano*}

\section{RESUMEN}

El objetivo de este trabajo es contribuir a la comprensión de la ayuda humanitaria de la Unión Europea (UE), con la entrada en vigor del Tratado de Lisboa (TdL), a partir del análisis del Reglamento (CE) 1257/96 del Consejo de la Unión Europea, del Consenso Europeo de la ayuda humanitaria de la Unión Europea (en vigor desde 2008) y del artículo 214 del Tratado de Funcionamiento de la Unión Europea (TFUE) del TdL.

En este trabajo se aborda el reto que tiene la uE para ofrecer una ayuda humanitaria independiente, al responder a las emergencias internacionales, al tiempo que trata de coordinar y dotar de mayor coherencia a su política exterior, a partir del análisis de la manera como la Unión concilia estos objetivos conflictivos. En particular, se estudia cómo interactúan las políticas de cooperación para el desarrollo y la de ayuda humanitaria de la UE, la política de comercio común, y la política exterior y de seguridad.

Por último, en las consideraciones finales se argumenta que a pesar de que la ayuda humanitaria se haya incorporado en el Tratado de Lisboa como una política más de su acción exterior, esta debe ser independiente, al estar sustentada en la solidaridad internacional, y

\footnotetext{
* Doctora en Ciencias Políticas y Sociología, Universidad Complutense de Madrid. Profesora investigadora del Programa de Estudios Políticos e Internacionales de El Colegio de San Luis. Ac. sLP (México) [eserrano@colsan. edu.mx].

Recibido: 24 de mayo de 2016 / Modificado: 27 de noviembre de 2016 / Aceptado: 8 de febrero de 2017

Para citar este artículo

Serrano, E. (2017). Retos de la política de ayuda humanitaria de la Unión Europea: entre la coherencia y la independencia. OASIS, 25, 9-39.
}

DOI: https://doi.org/10.18601/16577558.n25.02 
no en los principios aplicables al resto de las políticas de acción exterior, lo que dificulta establecer sinergias positivas con las otras políticas de la acción exterior de la UE.

Palabras clave: acción exterior, ayuda humanitaria, coherencia, coordinación, complementariedad, Unión Europea.

\section{Challenges of the European Union's humanitarian aid policy, between coherence and independence}

\section{ABSTRACT}

The aim of this work is to contribute to the understanding of humanitarian aid from the European Union (EU), from the entry into force of the Lisbon Treaty, starting from an analysis of Council Regulation (EC) No 1257/961, the European Consensus on humanitarian aid from the European Union (effective 2008) and article 214 TFEU of the Treaty of Lisbon.

This paper addresses the Eu's challenges in providing independent humanitarian aid when responding to international emergencies, while seeking to coordinate and enhance its foreign policy coherence; it also examines how the Union reconciles these conflicting objectives. In particular, it examines how EU development cooperation policy and EU aid policy, common foreign and security policy, and foreign policy interact.

Finally, it is argued in the concluding remarks that although humanitarian aid has been incorporated into the Lisbon Treaty as a further policy of its external action, it must be independent, as it is based on international solidarity, and not on the principles applicable to other policies of external action, making it difficult to establish positive synergies with the other policies of the eu's external action.

Key words: External action, humanitarian aid, coherence, coordination, complementarity, development to cooperation, European Union.

\section{INTRODUCCIÓN}

El establecimiento de un marco institucional internacional para paliar el sufrimiento humano a gran escala coincide con el final de la Primera Guerra Mundial.

Posteriormente, la Sociedad de Naciones y las Naciones Unidas designaron a estas poblaciones como "refugiados" e introdujeron una ley humanitaria que trataba de asegurar sus derechos. Los principios humanitarios justifican la acción humanitaria (principio de humanidad) y crean las condiciones de acceso para atender a los más necesitados (principios de imparcialidad, neutralidad e independencia).

Los orígenes de la ayuda de emergencia de la Comunidad Europea se remontan, prácticamente, a la propia formación de la Comunidad; pero no será hasta abril de 1992, con la creación de la Oficina Humanitaria de la Comunidad Europea (есно) -actual Dirección General de Ayuda Humanitaria y Protección Civil de la Comisión Europea (DG ECHO)-, que la Comunidad Europea se 
dota de un instrumento específico para hacer frente a las crisis humanitarias, con el fin de centralizar las decisiones y mejorar su gestión y coordinación ${ }^{1}$.

Su nacimiento no fue casual, este respondía a la necesidad de dar respuestas - al menos en el terreno humanitario- al conflicto de los Balcanes y a otras situaciones de crisis que se vivían en ese momento, y se integró dentro de una tendencia mundial de reforma del sector humanitario que hizo coincidir el nacimiento de la ECHO con la creación del Departamento de Asuntos Humanitarios de las Naciones Unidas. A fin de adecuar la maquinaria de la Comisión a los nuevos retos y problemas: aumento de emergencias complejas, crisis en los Balcanes, agravamiento de la situación en los Grandes Lagos, etc., la ECHO surgió en un momento en el que la UE no contaba con una política exterior común, y había grandes diferencias respecto a la posición que debía tomar en el conflicto de yugoslavo (19912001). Como han dicho Rey y Currea-Lugo (2002, p. 43), la ayuda humanitaria cumplía una función de diplomacia sustitutiva.

Con la aprobación del Reglamento (CE) 1257/96 del Consejo (Unión Europea, 1996, pp. 1-6) se consolida la ayuda humanitaria de la Comunidad y se dota de la base jurídica adecuada a labor de la ECHO, se asumen los principios de imparcialidad y neutralidad, se reconoce la necesaria independencia de las ONG -que son las encargadas de ejecutar la ayuda comunitaria- y se separa claramente la acción humanitaria de la política exterior de la Unión, que en esos momentos estaba en proceso de construcción. De este modo, la Comisión Europea cuenta-desde 1992-con un instrumento ágil y eficaz para responder a los desastres naturales, a los conflictos armados y a otras situaciones similares (Rey, 2005, p. 118). Durante estos ańos, la UE se ha convertido en el primer donante mundial de ayuda humanitaria-sumando las aportaciones de los Estados miembros y de la Comunidad- (p. 119) (figura 1).

Hay que señalar que, desde 1993, la ECHO casi ha duplicado su presupuesto, que para 2016 fue de 1.175 millones de $€$. De esta manera, la ECHO (ahora DG ECHO) ha ampliado su campo geográfico de actuación que en un primer momento afectó a más de cuarenta países y territorios de todo el mundo, y en 2016 la ayuda se extendió a unos 80 países afectados por catástrofes naturales, crisis armadas emergentes, así como complejas y crónicas. Como se observa en la figura 1, en la actualidad la uE es el principal donante de ayuda humanitaria en todo el mundo. La Unión -la Comisión Europea (CE) y los Estados miembros (EEMM) - suministra más de la mitad de los fondos necesarios para brindar ayuda de emergencia a las víctimas de catástrofes naturales o provocadas por el hombre a escala mundial, y promueve activamente el respeto por el derecho internacional humanitario

1 Creada el 1 de marzo de 1992, la Echo estuvo inicialmente asignada a la Comisaría de Pesca, pero en la actualidad es una Dirección General (DG) de la Comisión Europea. Nació como un órgano autónomo de la entonces DG VIII, que dependía políticamente del vicepresidente de la Comisión Europea. 


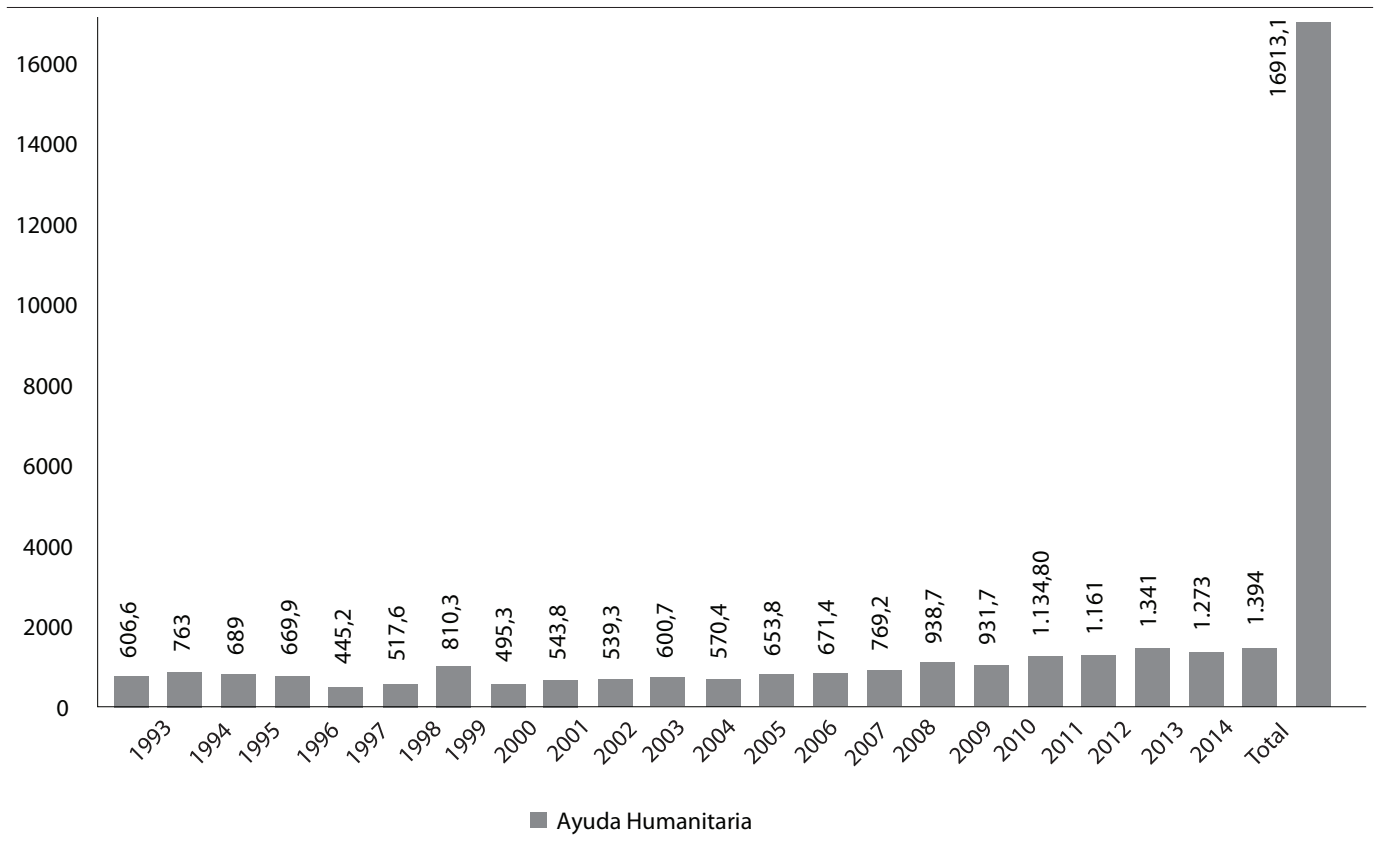

Fuente: elaboración propia a partir de datos de la $\mathrm{ECHO}^{2}$.

(DIH). En los últimos años, la evolución de las partidas presupuestarias ${ }^{3}$ destinadas por la CE a la ayuda humanitaria (figuras 1 y 2) muestra un incremento sostenido. Este se produce en relación con el mayor número y complejidad de las crisis humanitarias, y con la persistencia de crisis crónicas infrafinanciadas. Pero el incremento de los fondos comunes no es suficiente, por lo que se debe fomentar una mayor coherencia y coordinación en las políticas

2 Informes de la Comisión Europea del año 1993-2015.

3 Las operaciones humanitarias se financian a partir del presupuesto de la uE (Título 23), destinado a la ayuda humanitaria y la protección civil. Con la aprobación de la autoridad presupuestaria, este presupuesto puede aumentar, movilizando fondos de la Reserva de Ayuda de Emergencia (EAR) (Título 40) destinada a responder a las necesidades derivadas de acontecimientos imprevisibles. Otras fuentes son las transferencias desde otras líneas presupuestarias, como la rúbrica destinada a la ayuda exterior y, en el caso de los países ACP, las reservas del FED (dotación B). En los 18 ańos de su existencia, la DG ECHO ha tenido que solicitar aumentos presupuestarios cada año. Hay que señalar que la uE, en el marco financiero plurianual (MFP) (2007-2013) destinó 5.600 millones de € a la ayuda humanitaria, cantidad que se ha incrementado periódicamente para hacer frente a emergencias y crisis. En el MFP (2014-2020) se incrementó la asignación presupuestaria para el instrumento de la ayuda humanitaria, que ascendió a 6.621,70 millones de € (es decir, una media anual de 915 millones de $€$, en lugar de los 813 millones de $€$ del periodo anterior). 
FIGURA 2. EVOLUCIÓN DE LA ASIGNACIÓN DE LA COMISIÓN EUROPEA A LA DG ECHO (2011-2014)

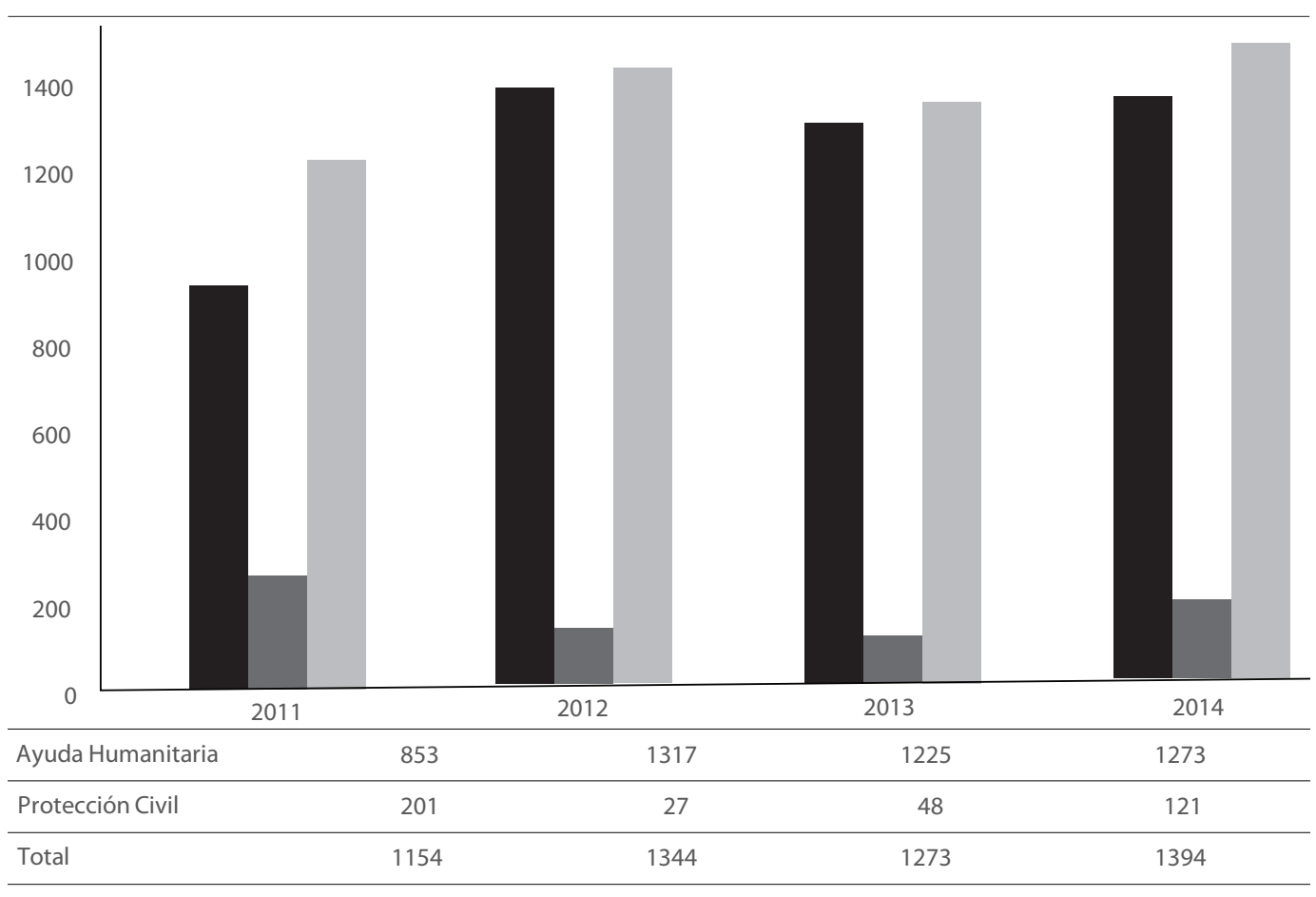

Fuente: elaboración propia a partir de Informes de la сом (2011) 343 final, сом (2012) 489 final, сом (2013) 658, final, com (2014) 537 final, сом (2015) 406, final.

de ayuda humanitaria y un incremento en la coordinación a través del intercambio de información de los países para mejorar la eficiencia de la respuesta global de la UE a estas crisis.

Hay que decir que la acción comunitaria de asistencia humanitaria de la UE presenta un doble aspecto: ayuda y rehabilitación y reconstrucción, aunque las fronteras que materialmente las separan no sean claras.

Respecto a los actores, a nivel interno la UE no tiene muchos problemas para crear las sinergias y desarrollar medidas humanitarias; a nivel externo reconoce el liderazgo de la Organización de las Naciones Unidas (ONU) en la ayuda humanitaria. La UE colabora bilateralmente con cada uno de los organismos especializados de la $\mathrm{ONU}^{4}$, en la financiación de la ejecución de la asistencia humanitaria a través de estos organismos, organizaciones internaciones no gubernamentales humani$\operatorname{tarias}^{5}$ y organizaciones no gubernamentales humanitarias (nacionales).

\footnotetext{
4 Organizaciones humanitarias especializadas tales como ACNUR, OMS, UNICEF, UNRWA, FAO, OCHA, entre otras.

5 Comité Internacional de la Cruz Roja, Federación Internacional de la Cruz Roja.
} 
FIGURA 3. CANALIZACIÓN DE LOS FONDOS DE LA ECHO A TRAVÉS DE CONTRATOS

CON ORGANIZACIONES HUMANITARIAS (2008-2015)

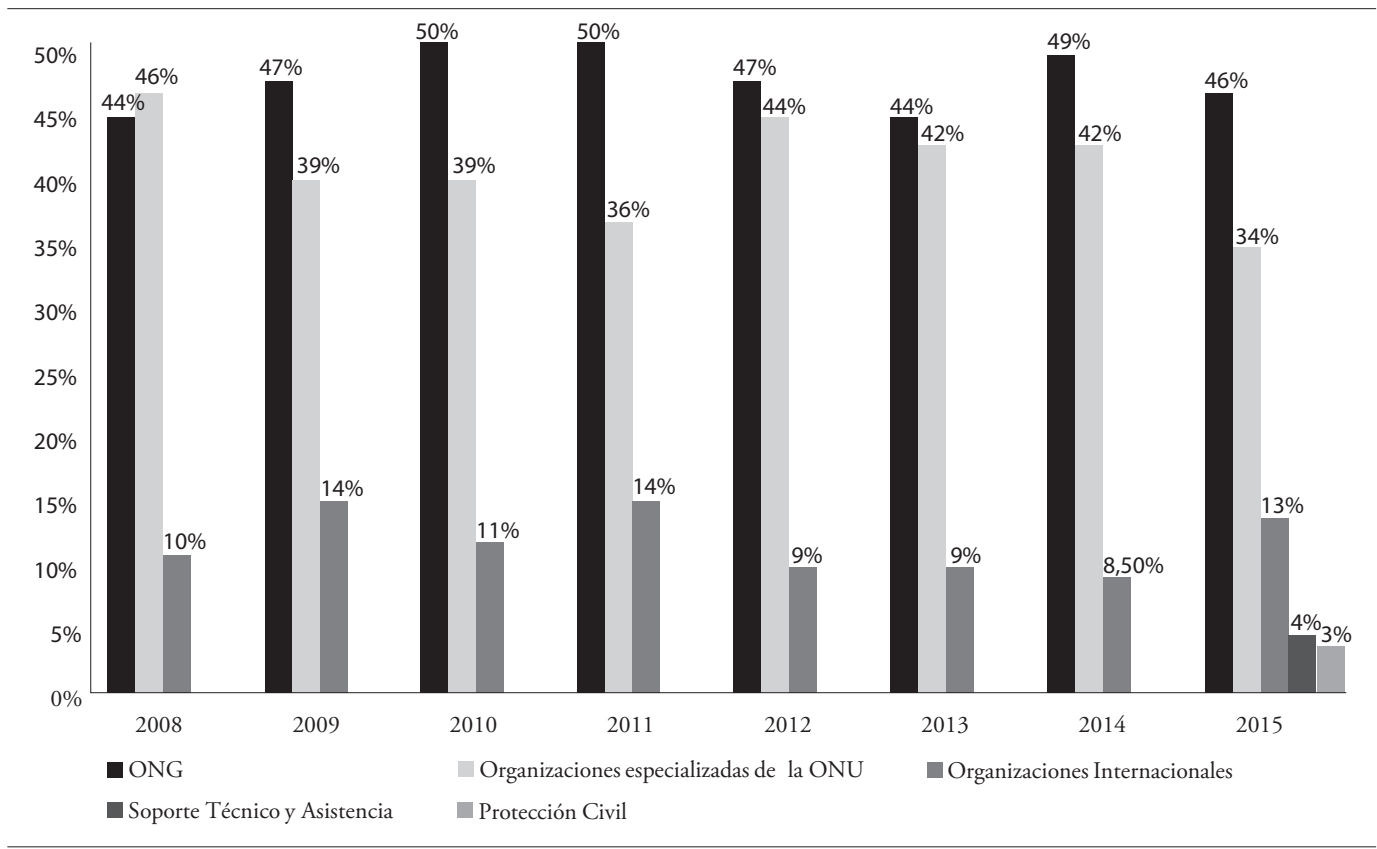

Fuente: elaboración propia a partir de Comisión Europea, Informe Anual de ayuda humanitaria y protección civil, 2008, 2009, 2010, e Informe Anual de la DG ECHO a, 2011, 2012, 2013, 214, 2015.

La DG ECHO no interviene directamente sobre el terreno, sino que distribuye y presta su asistencia a través de sus socios. El $88 \%$ del presupuesto fue gestionado por la ECHO, pero se canalizó para su ejecución a través de 200 socios con los que la Oficina tiene firmado el acuerdo de asociación para ejecutar la ayuda humanitaria. Como se observa en la figura 3 , el $93 \%$ del presupuesto asignado por la ECHO en 2014 fue canalizado a través de 200 socios con los que la UE ha firmado acuerdos marco de asociación para ejecutar la ayuda humanitaria (figura 3).

A partir de la entrada en vigor del Tratado de Lisboa $(\mathrm{TdL})^{6}$, y teniendo en cuenta el nuevo contexto institucional establecido, la UE dispone del potencial y de la ambición necesaria para hacer su acción exterior más coherente, eficaz y estratégica, recurriendo a su amplia gama de recursos e instrumentos.

6 "Versiones Consolidadas del Tratado de la Unión Europea y del Tratado de Funcionamiento de la Unión Europea”, en Diario Oficial de la Unión Europea C-83/1, 30.03.2010, Bruselas. En el Tratado de Lisboa aparecen en realidad dos tratados internacionales distintos: El Tratado de la Unión Europea (TUE) y el Tratado de Funcionamiento de la Unión Europea (TfUE). La Unión Europea dedica la Parte V del Título III del Tratado de Funcionamiento de la UE a la acción exterior. 
Este artículo aborda la ayuda humanitaria de la Unión Europea como parte de su acción exterior, y analiza la coherencia y la coordinación con las otras políticas al respecto establecidas en el TdL. Así mismo, se analiza el reto que tiene la Unión al querer entregar ayuda humanitaria que sea independiente de los objetivos de política exterior.

El preámbulo del Reglamento 1257/96 del Consejo sobre la ayuda humanitaria proporciona el marco jurídico básico para la posterior elaboración de una política de ayuda humanitaria específica en nombre de la Comunidad Europea (ahora Unión Europea), y hace referencia explícita al imperativo humanitario, destacando que el objetivo esencial de la ayuda humanitaria es prevenir o aliviar el sufrimiento humano independientemente de cualquier consideración política (Unión Europea, 1996). Según el Reglamento 1257/96 del Consejo, la respuesta humanitaria de la UE viene determinada únicamente por las necesidades de las víctimas y no debe estar condicionada ni subordinada a otras políticas. La voluntad de luchar por una política de ayu- da humanitaria de una UE más independiente -autónoma de consideraciones económicas, políticas y militares-, en cumplimiento del derecho internacional humanitario, quedó clara durante la redacción de la Constitución por la Convención Europea en 200-2003. En ella se subrayó la naturaleza independiente de la ayuda humanitaria en comparación con otras políticas de la acción exterior de la UE, tales como la cooperación al desarrollo o la Política Exterior de Seguridad Común (PESC).

El Consenso Europeo sobre ayuda humanitaria, aprobado en diciembre de 2007 (European Union, 2008), destacó la naturaleza independiente de la política comunitaria en este campo y estableció que la ayuda humanitaria de la UE debe guiarse por los cuatro principios -neutralidad, imparcialidad, humanidad e independencia- ${ }^{7}$ acordados a nivel internacional, que son específicos de la ayuda humanitaria (cuadro 1); y que distingue de otros tipos de ayuda (de emergencia ${ }^{8}$, alimentaria', ayuda a los refugiados y a las personas $\left.\operatorname{desplazas~}^{10}\right)$.

\footnotetext{
7 Estos cuatro principios son específicos a la ayuda humanitaria y la hacen distinta de otras formas de ayuda.

8 La ayuda de urgencia pretende hacer frente a los problemas provocados por catástrofes naturales, y para ser eficaz ha de ser flexible y rápida. Por lo común, es una ayuda que se presta en efectivo, a fin de adquirir productos de primera necesidad (alimentos, medicamentos, combustible) o realizar trabajos de reconstrucción tras un desastre.

La ayuda alimentaria, programa que inició la UE en 1968, pretende contribuir al abastecimiento alimentario - proporcionando productos- de poblaciones desnutridas como consecuencia de crisis naturales, tales como sequias y otras calamidades. La ayuda alimentaria que ofrece la ECHO consiste en la aportación de productos alimentarios a los países en vías de desarrollo, con el objeto de potenciar su autoabastecimiento y garantizar su seguridad alimentaria. Así mismo, la ЕСHo es considerada como un instrumento horizontal de la política de cooperación al desarrollo de la UE.

10 La ayuda a los refugiados tiene por finalidad socorrer a las poblaciones expulsadas de su propio país u obligadas a dejarlo por razones de guerra, persecución y otras situaciones difíciles. Su finalidad es la de prestar asistencia entre las fases de éxodo y de reasentamiento en otro país o de reintegración en el de origen.
} 
CUADRO 1. PRINCIPIOS HUMANITARIOS ESTABLECIDOS EN EL CONSENSO DE 2007

\begin{tabular}{|c|c|c|c|c|}
\hline Humanidad & Neutralidad & Imparcialidad & Independencia & $\begin{array}{c}\text { Basado en las } \\
\text { necesidades }\end{array}$ \\
\hline $\begin{array}{l}\text { El sufrimiento } \\
\text { humano debe paliarse } \\
\text { allá donde se encuen- } \\
\text { tre, con especial aten- } \\
\text { ción a las personas más } \\
\text { vulnerables. }\end{array}$ & $\begin{array}{l}\text { La ayuda humanitaria } \\
\text { no debe favorecer a } \\
\text { ninguna de las par- } \\
\text { tes implicadas en un } \\
\text { conflicto armado o de } \\
\text { otro tipo. }\end{array}$ & $\begin{array}{l}\text { La ayuda humanitaria } \\
\text { debe proporcionarse } \\
\text { únicamente en función } \\
\text { de las necesidades, sin } \\
\text { discriminación entre o } \\
\text { dentro de las poblacio- } \\
\text { nes afectadas. }\end{array}$ & \begin{tabular}{|l|} 
Los objetivos huma- \\
nitarios deben ser \\
independientes de \\
los objetivos políticos, \\
económicos y militares. \\
El único propósito de \\
la ayuda humanitaria \\
es aliviar y prevenir el \\
sufrimiento de las víc- \\
timas de emergencias \\
humanitarias.
\end{tabular} & $\begin{array}{l}\text { Ayuda humanitaria } \\
\text { está destinada a pre- } \\
\text { servar la vida, prevenir } \\
\text { y aliviar el sufrimiento } \\
\text { humano y mantener la } \\
\text { dignidad humana. }\end{array}$ \\
\hline
\end{tabular}

Fuente : Policy Departament, DG EXPO, European Union.

Con la entrada en vigor del TdL en 2009, la ayuda humanitaria se convierte en una política de la acción exterior de la UE por derecho propio. Significativamente, el artículo 214 del TFUE (Comunidades Europeas, 2010, p. 143), fue copiado textualmente del Tratado Constitucional de 2004 (Comunidades Europeas, 2004, p. 1). El TdL estableció los principios, fines y objetivos de la "Acción Exterior de la UE"; para la consecución de esos objetivos, $y$ al igual que la Pesc, el Tratado propone mantener la coherencia y coordinación entre los diferentes ámbitos de la acción exterior comunitaria de la Unión, y entre estos y las demás políticas. Al entrar en vigor el TdL, la ayuda humanitaria pasa a ser una competencia compartida paralela, lo que significa que la UE aplicará una política propia y los Estados miembros podrán hacer lo mismo evitándose que la actuación de la Unión sea un complemento de las políticas nacionales.

El Consenso Europeo de ayuda humanitaria es el documento más reciente en el que se da la definición y las características básicas de la política de ayuda humanitaria de la Unión. En este se reconoce de manera explícita la ayuda humanitaria como una obligación moral, y la necesidad de la concesión de asistencia $a d h o c$, y alivio y protección para personas de terceros países que son víctimas de los desastres naturales y aquellos provocados por el hombre; de esta manera, constituye una política distinta de la acción exterior de la UE (art. 214 TFUE) y es un paso importante hacia el logro de la meta de la ayuda humanitaria independiente.

La coordinación y coherencia de las actividades externas de la UE se ha buscado desde el Tratado de Maastricht, lo que se traduce en el establecimiento de sinergias positivas entre las diferentes políticas exteriores. Como se verá más adelante, el TdL concede gran importancia a este objetivo en la acción exterior de la UE (Gebhard, 2001, pp. 101-127), basándose en la suposición de que mediante el establecimiento de una estrategia para la consecución de un fin común, la Unión se convierta en un actor de política exterior más 
eficiente y eficaz. Dada la estrecha conexión entre el origen de una crisis humanitaria -una guerra civil, desastres naturales y la pobreza extrema- y sus consecuencias -un gran número de personas desplazadas y dificultades sociales y económicas-, la ayuda humanitaria casi está automáticamente vinculada a otros ámbitos de la política. Por tanto, uno de los principales retos para la Unión en la actualidad es garantizar la coordinación, la coherencia en sus diferentes dimensiones -estratégica y técnica- y la consistencia en su respuesta a situaciones de crisis entre las diferentes políticas involucradas, al mismo tiempo que defiende dicha coherencia con otras políticas exteriores.

La coherencia es condición necesaria para una política exterior eficaz, no solo de la Unión, sino de todos los actores internacionales involucrados. Podríamos decir que la coherencia y el enfoque multilateral son los principios que guían la acción exterior de la UE.

La DG ECHO de ayuda humanitaria y protección civil es la encargada en la actualidad de dar respuesta a las emergencias y facilitar ayuda a países no pertenecientes a la UE para que refuercen sus capacidades de respuesta ante las crisis, y así contribuir a su desarrollo a largo plazo. El programa de resiliencia que establece la Comunicación de la Comisión, de 3 de octubre de 2012, titulado "El planteamiento de la UE sobre la resiliencia: aprender de las crisis alimentarias" (Comisión Europea, 2012), y el Plan de acción para la resiliencia de 2013, así como el objetivo de mejorar el vínculo entre la ayuda de emergencia, la rehabilitación y el desarrollo, forman parte de la programación de la DG ECHO. Aumentar la resiliencia es el eje central de dos programas emblemáticos, la Alianza Mundial para la Iniciativa de Resiliencia (AGIR), en el Sahel, y SHARE, en el Cuerno de África, destinados a coordinar la ayuda humanitaria y el desarrollo, y a romper el círculo vicioso de cambio climático, hambre y pobreza.

Las actividades de reducción del riesgo de catástrofes son otro aspecto de la gran importancia que la DG ECHO da a la resiliencia. Los programas de preparación ante catástrofes de la DG eCho (Dipecho) en Asia, América Latina y el Caribe apoyan los sistemas de alerta temprana, las campañas de sensibilización y otras medidas preventivas. La UE es un agente relevante a la hora de configurar los intentos de gestión del riesgo de catástrofes por parte de la comunidad internacional.

La ambiciosa visión que tiene la UE para el futuro se halla expuesta en la Comunicación de abril de 2014 titulada "Marco de Acción de Hyogo posterior a 2015: gestionar los riesgos para lograr la resiliencia" (Comisón Europea, 2014), presentada como parte de los preparativos de la Conferencia Mundial de las Naciones Unidas sobre la Reducción del Riesgo de Desastres, celebrada en marzo de 2015 en Sendái (Japón). Paralelamente a las operaciones de emergencia iniciadas cuando se produce una crisis, la UE se compromete a trabajar para reducir los riesgos y la vulnerabilidad, y a preparar a la población ante catástrofes naturales a escala local, nacional y regional, basándose en el Marco de acción de Hyogo (sustituido en marzo de 2015 por el Marco de Sendái para la reducción del riesgo de desastres [2015-2030]). 
Para ello, el trabajo se ha dividido en dos secciones. En la primera se describe la acción exterior de la UE en el TdL. En la segunda sección se analiza el desafío legal al que se enfrenta la UE al coordinar la entrega de la ayuda humanitaria, manteniendo el principio de "independencia"; al tiempo que esta debe ser coherente con los objetivos y principios de la acción exterior de la UE -es decir, la política de cooperación al desarrollo (arts. 209-211 del TFUE), la política exterior y de seguridad común, y la política comercial (art. 207 del tFue) - .

Para la realización de este trabajo se recurrió a la revisión documental y de fuentes hemerográficas e institucionales (documentos oficiales de la Unión Europea, y publicaciones tales como el Tratado de Lisboa de 2009 y el Consenso Europeo de Ayuda Humanitaria; entre otros), así como de artículos especializados e investigaciones que nos ayudaron a conocer más de cerca la complejidad de la ayuda humanitaria como una política más de la acción exterior de la Unión Europea y su coherencia y coordinación con otras acciones -de emergencia- y políticas comunitarias.

\section{LA ACCIÓN EXTERIOR DE LA UNIÓN EUROPEA EN EL TRATADO DE LISBOA}

La acción exterior de la UE es tan extensa como compleja de abordar. En la actualidad, la UE pasa por un periodo de cambio, resultado de la entrada en vigor del TdL, que reformó en gran medida cuestiones relativas al funcionamiento de la Unión, en cuanto a la estructura institucional y a la toma de decisiones.
Resultado de lo anterior, se inició una nueva etapa para la acción exterior, y en particular para la ayuda humanitaria comunitaria, que pasa a constituirse en uno de los mecanismos de la acción exterior de la Unión y queda sometida a la estrategia "Unity of Command" (Peterson, 2007, p. 7). Gracias al TdL, la Unión parece estar en condiciones de expresarse con una sola voz ante sus socios internacionales, poniendo en juego todas las capacidades económicas, humanitarias, políticas y diplomáticas para defender sus interés y valores en todo el mundo, respetando a su vez los intereses particulares de los Estados miembros en el marco de sus relaciones exteriores. Este hecho ha supuesto el paso de la ayuda humanitaria comunitaria a su integración en uno de los mecanismos de la acción exterior comunitaria, que por fin goza de una personalidad jurídica internacional (art. 47 TUE del TdL) (Fride, 2010, p. 10). El que a la UE se le reconozca explícitamente su personalidad jurídica no altera el hecho de que siga siendo una organización internacional supranacional, la plenitud de las competencias la tienen los Estados miembros. Debido a ello, son los Estados miembros los que le "atribuyen competencias para alcanzar sus objetivos comunes" (art. 1.1. del TUE del TdL). La UE intentó difuminar la distinción del pilar supranacional y la cooperación intergubernamental como vías para la construcción europea, pero no lo consiguió, y hoy en día las relaciones exteriores de la Unión siguen divididas en dos sectores: la acción exterior "comunitarizada" y la acción exterior intergubernamental, es decir, la PESC, y la Política Exterior de Seguridad Común 
(PESD), ahora denominada Política Común de Seguridad y Defensa (PCSD).

El TdL introdujo una definición más detallada e integrada de la acción exterior de la UE, y definió un conjunto de objetivos y valores a los que se supeditan cada una de las políticas de la acción exterior comunitaria, más allá de sus propios objetivos. En el TFUE se incorporaron las novedades introducidas por la Constitución Europea non nata, que agrupó bajo la expresión "acción exterior" un conjunto de políticas heterogéneas, antes dispersas en el TUE y el TCE (arts. III-292 a III-329) (Comunidades Europeas, 2004). Tal agrupación pudo tener un propósito sistematizador, pero no uniformaba la naturaleza de las políticas en cuestión, por el contrario, el TdL volvió a separar la acción exterior de la PESC, lo que sigue sin responder a un criterio sistematizador, pues las políticas que contiene son de naturaleza diferente (supranacional e intergubernamental). La acción exterior comunitaria es objeto del Título $\mathrm{v}$ del TUE del TdL "Disposiciones generales relativas a la política exterior y de seguridad común”, y de la Parte v del true "Acción exterior". El Capítulo I del Título v del Tue del TdL -arts. 21 a 46 TuE- (Comunidades Europeas, 2010, pp. 28-41) es común tanto a la acción exterior "comunitarizada" como a la PESC/ PCSD. Sin embargo, a partir de ahí van por diferentes caminos, aunque el hecho de que haya disposiciones comunes establece un lazo de unión que está reforzado por la necesidad de que la UE vele por la coordinación y cohesión entre los distintos ámbitos de acción exterior, y entre estas y las demás políticas. Todas estas políticas o acciones, a excepción de la "cláusula de solidaridad", estaban ya contempladas en el TCE.

El TFUe define la "acción exterior de la Unión Europea" (como un conjunto de políticas de diferente naturaleza agrupadas en la Parte v-artículos 205 a 222 del TfUE) (Comunidades Europeas, 2010, pp. 139-149). La estructura descrita pone de relieve una primera división de las competencias exteriores de la UE, en dos grandes categorías. Por un lado, la PESC, regulada por el TUE del TdL, sobre cuya naturaleza no se pronuncian los Tratados, y que se mantiene dentro del marco de cooperación intergubernamental. El carácter intergubernamental de la PEsc se intentó maquillar con la calificación de "competencia específica" (arts. 24.1. y 24.2 del TUE del TdL y 2.4 del TFUE), en la que las decisiones se siguen adoptando por la regla de la unanimidad (y no por mayoría). Por otro lado, las demás políticas de la UE, reguladas en el TFUE, especifican si se trata de competencias de naturaleza exclusiva, compartida, de coordinación, de apoyo o complementaria. Lo único que une a ambos conjuntos de políticas son los principios que regulan la acción exterior de la UE y la PESC, que quedan establecidos en los artículos 21 y 22 del tue de Lisboa (pp. 28-29), aunque lo hacen con diferente intensidad, en las distintas políticas. El artículo 21 del TUE del TdL establece los principios generales:

El fomento de la democracia, del Estado de derecho y de la universalidad e indivisibilidad de los derechos humanos y de las libertades fundamentales, el respeto a la dignidad humana, los principios de igualdad y solidaridad y el respeto de los principios 
de la Carta de las Naciones Unidas y del Derecho Internacional (p. 163).

En la incorporación del artículo 21 del TUE del TdL (Comunidades Europeas, 2010, pp. 29-30) dentro de las disposiciones generales de la acción exterior de la Unión, se añadió el compromiso de esta con el enfoque multilateral para la solución de problemas internacionales, en especial en el ámbito de la Organización de las Naciones Unidas. El TUE del TdL estableció los objetivos comunes a toda su acción exterior, siendo uno de ellos ayudar a las poblaciones, países y regiones que se enfrentan a catástrofes naturales o de origen humano (p. 29). Esta declaración de principios y objetivos nos ofrece la imagen de una Unión con la voluntad de asumir responsabilidades en la gestión de los problemas internacionales, en especial en lo referente al mantenimiento de la paz mundial y la cooperación en un marco de solidaridad. El artículo 22 del TUE del TdL (pp. 29-30) por su parte, se ocupa del procedimiento de acción y de la participación de las instituciones en el marco común de la acción exterior, señala además el papel predominante del Consejo Europeo en la acción exterior -que actúa por unanimidadal ser el encargado de establecer los intereses y objetivos estratégicos en los que se basará esta. También deja clara la distinción entre la Política Exterior de Seguridad Común y "los demás ámbitos de la acción exterior”.

Según lo establecido en el artículo 7 del TFUE, la Unión "velará por la coherencia entre sus diferentes políticas y acciones, teniendo en cuenta el conjunto de sus objetivos". La tarea de velar por la coherencia y coordinación de los diferentes ámbitos de la acción exterior y entre la política de ayuda humanitaria y las demás políticas es encomendada al Consejo, la Comisión y el Alto Representante de la UE para Asuntos Exteriores y Política de Seguridad (Comunidades Europeas, 2010, pp. 1719). El artículo 47 del tue del TdL dota a la uE de personalidad jurídica. La personalidad jurídica internacional conlleva tres atributos principales: la capacidad para celebrar acuerdos o tratados internacionales, el derecho de legación activo y pasivo, y la posibilidad de ser sujeto activo y pasivo de responsabilidad internacional. La actuación de la UE en la esfera internacional puede ocasionar perjuicios a terceros Estados o a sus nacionales y a otras organizaciones internacionales. Así mismo, la UE puede experimentar violaciones de sus derechos en la esfera internacional por parte de otras organizaciones internacionales. El problema no se plantea tanto a nivel de principios como en el plano práctico, teniendo en cuenta la atribución de competencias de los EEMM de la Unión, y la distribución de las mismas que puede ser difícil determinar quién es el sujeto responsable, si los EEMM directamente implicados o la UE. Las normas establecidas en el TFUE respecto a la ayuda humanitaria ponen énfasis en las coordinaciones a las que se ve sometida la ayuda humanitaria en la que diversos sujetos y actores participan.

\section{EN BUSCA DE LA COHERENCIA EN LA ACCIÓN EXTERIOR DE LA UNIÓN EUROPEA}

Dada la estrecha relación entre los orígenes de una crisis humanitaria y sus consecuencias, la ayuda humanitaria solo puede ser eficaz cuan- 
do está vinculada a otras políticas. La UE, en su respuesta a las emergencias internacionales, tiene que garantizar la coherencia entre dicha ayuda y las otras políticas exteriores involucradas. Pero asegurar esta coherencia puede socavar la independencia de la política de ayuda humanitaria de la Unión.

La coherencia es definida como la ausencia de contradicciones entre las diferentes áreas de la política exterior y el establecimiento de sinergias entre ellas (Gauttier, 2004, pp. 2326; Gebhard, 2011, p. 106; van Elsuwege, 2010, pp. 113-114), y como las diferentes políticas de la UE para beneficiar a los países en vías de desarrollo e incrementar la efectividad de la cooperación para el desarrollo (Portela y Kolja, 2009, pp. 3-5). En términos de política, la coherencia se refiere a la obligación de asegurar la sinergia entre los distintos ámbitos de la acción exterior de la uE, lo que implica "una forma conveniente y positiva de la interacción entre las [políticas] y sus respectivas burocracias, unido al servicio de un propósito común" (Gebhard, 2001, p. 112). En la práctica, se pueden distinguir dos dimensiones de la coherencia. Por un lado, está la estratégica o la relacionada con las políticas, con la posibilidad de crear conflicto entre los objetivos y principios, o en las diferentes agendas políticas de la acción exterior. Por otro lado, está la dimensión técnica o de procedimiento, que apunta a las "consecuencias administrativas de tener que conciliar dos canales diferentes de la formulación de políticas, incluidas sus respectivas maquinarias burocráticas" (p. 106). El logro de la coherencia, por tanto, puede ser frustrado por cualquiera de las incompatibilidades operativas o de procedimiento, o debido a los conflictos que surgen por competir por objetivos políticos, diferentes culturas burocráticas, lucha por el poder institucional, o rivalidad entre las instituciones.

Dada la estrecha relación entre los orígenes de una crisis humanitaria y sus consecuencias, en su respuesta a las emergencias internacionales, la UE tiene que garantizar la coherencia entre la ayuda humanitaria y las otras políticas exteriores involucradas, tales como la política de cooperación al desarrollo, la gestión de crisis y la política comercial con el riesgo de socavar la independencia de su política al respecto.

La preocupación de la UE por la coherencia de su acción exterior es un tema que ha sido abordado por varios autores tales como Gauttier (2004), Gebhard (2011), Nuttall (2005), Smith (2004), van Elsuwege y Orbie (2014). En general, se supone que una mayor coherencia afecta positivamente la eficacia de la acción exterior de la $\mathrm{UE}^{11}$.

11 En el TdL hay que señalar los principios de coherencia tanto vertical como horizontal. De acuerdo con el artículo 21.3 del TUE de Lisboa, "La Unión velará por mantener la coherencia entre los distintos ámbitos de su acción exterior y entre estos y sus demás políticas. El Consejo y la Comisión, asistidos por el Alto Representante de la Unión para Asuntos Exteriores y Política de Seguridad, garantizarán dicha coherencia y cooperarán a tal efecto”. Como se puede observar, la redacción y el contenido del artículo es similar al artículo 3 del tue de Niza. A pesar de ello, los órganos encargados de garantizar la coherencia eran el Consejo y la Comisión, y ahora en el TdL el Alto Representante es el encargado de garantizar la coherencia horizontal. 
RETOS LEGALES: ENTRE LA COHERENCIA E INDEPENDENCIA DE LA AYUDA HUMANITARIA DE LA UNIÓN EUROPEA

La ayuda humanitaria forma parte de la acción exterior de la UE compartiendo el Título III, "Cooperación al desarrollo con terceros países y ayuda humanitaria”, con la cooperación económica, financiera y técnica con terceros países y organizaciones internacionales. Con el TdL, la uE adquirió nuevos instrumentos de acción exterior que le permiten desarrollar una política exterior más activa y unificada. El artículo 214 del TFue del TdL dota a la ayuda humanitaria de una base jurídica propia -independiente de la política de desarrollo-, que la eleva a la categoría de política de la acción exterior de la ue (art. 214 del TFue.) (Comunidades Europeas, 2010, p. 143).

La búsqueda de coordinación y coherencia es difícil y problemática para la política de ayuda humanitaria debido al objetivo declarado de independencia. Por ello, se plantea la duda de si la inserción en un capítulo aparte en el TdL, separado de la política de cooperación para el desarrollo de la UE, ha reforzado la independencia de la ayuda humanitaria, o si esta búsqueda puede subordinar el imperativo humanitario a los principios y metas de seguridad, desarrollo y comercio.

La naturaleza de la competencia de la UE en materia de ayuda humanitaria es complementaria según lo establecido en el artículo 214.1 del TFUE, el cual señala que las acciones de ayuda humanitaria, realizadas tanto por la UE como por sus EEMM, "se completarán y se reforzaran mutuamente" (Comunidades Europeas, 2010). Aquí la Unión tiene una competencia compartida derogatoria (art. 4.4 del TFUE), es decir, que "la Unión dispondrá de competencias para llevar a cabo acciones y una política común, sin que el ejercicio de esta competencia pueda tener por efecto impedir a los Estados miembros ejercer la suya" (p. 52 ), lo que incide en la actuación conjunta, cuya coordinación estrecha debe mantenerse en el doble plano de adopción de decisiones y sobre el terreno (Reglamento 1257/96). En el caso del mecanismo de protección civil la UE funciona como complemento de la ayuda humanitaria.

En este sentido, la Unión puede dirigir su política comunitaria y sus acciones de ayuda humanitaria de forma complementaria a las de los EEMM -diferente a lo que ocurre con las competencias compartidas clásicas-, sin bloquear la actividad individual de estos en la materia. La actuación de la ayuda humanitaria de la UE se habría reforzado si el TFUE hubiera reconocido a la protección civil el mismo tipo de competencia compartida. Respecto a la protección civil, el artículo 6 (f) del TFue prevé que la ue dispondrá de una competencia de apoyo, coordinación o complementaria de la de los EЕMм que la componen, y que el TdL ha creado una base jurídica específica para esta materia -el artículo 196 del TFUE-, quedando fuera de la "acción exterior de la Unión" ${ }^{2}$.

12 Este artículo pertenece al Título XxiII de la Parte in del TFue dedicado a las "Políticas y acciones internas de la Unión”. 
La incorporación de estos artículos en el TdL no significa que la UE no tuviera competencia para actuar previamente. De hecho, estas disposiciones crean nuevas bases jurídicas explícitas para una práctica que se ha incrementado con el uso de otros poderes en virtud de los tratados.

La consecución de los objetivos de la acción exterior de la Unión se ve obstaculizada por el DIH, con el único propósito legítimo de la ayuda humanitaria de aliviar y prevenir el sufrimiento de las víctimas de estas crisis. Hay que señalar que el TdL no dice nada al respecto, solo hace referencia a la "imparcialidad, neutralidad y no discriminación” como los principios fundamentales que guían la ayuda humanitaria de la UE (art. 214.2 del TFUe) (Comunidades Europeas, 2010, p. 143). A pesar de la ausencia de una referencia explícita a los principios de humanidad e independencia en el TdL, estos todavía se unen a las instituciones y los Estados miembros en la búsqueda de la política de ayuda humanitaria de la UE, entre otras cosas porque el tratado contiene una referencia a "los principios del derecho internacional” (art. 214.2 TFUE). La noción de independencia en estos últimos puede considerarse como un "principio derivado", debido a su contenido, es decir, la autonomía de los objetivos humanitarios de la política militar o influencias económicas se desprende de los otros tres principios.

Debido a que el objetivo de la ayuda humanitaria es independiente es de jure y no está reconciliado con el objetivo de una política exterior más coherente, por lo que depende en gran medida de cómo se interpretan las respectivas disposiciones del $\mathrm{TdL}$ y del Consenso
Europeo de Ayuda Humanitaria (2007). Por un lado, el conflicto entre "la independencia y la coherencia" surgió en la primera parte de la prestación de la ayuda humanitaria en el TdL: la ayuda humanitaria de la UE no solo se aplicará cumpliendo los principios generales del derecho internacional (humanitario), sino que también se llevará a cabo "en el marco de los principios y objetivos de la acción exterior de la Unión” (art. 214.1 del TFUE). Es importante señalar que esta referencia se incluye como una cláusula estándar en todas las disposiciones de los tratados que se ocupan de las políticas exteriores de la UE y refleja una preocupación general del TdL de garantizar la coherencia de la acción exterior de la Unión en la escena internacional. Sin embargo, una lectura más detallada del artículo 214.1 del TFue podría sugerirnos que la ayuda humanitaria puede ser utilizada como un instrumento para conseguir la lista completa de los objetivos mencionados en el artículo 21 del tue, que es el punto de referencia en el que se establecen los principios y objetivos generales de la UE. Estos incluyen el objetivo de "preservar la paz, prevenir los conflictos y fortalecer la seguridad internacional" (art. 21.2 (c) del TUE); tal interpretación afecta potencialmente la independencia de las operaciones humanitarias. Sin embargo, la inclusión de una lista horizontal de los objetivos de la acción exterior en el artículo 21 del TUE no exime a las instituciones de respetar el principio de atribución como se expresa en las bases jurídicas específicas mencionadas en los tratados (Dashwood, 2011, p. 35).

El artículo 214.2 del true señala que los principios que guían la actuación de la UE en materia de ayuda humanitaria son específi- 
cos para este sector, y distintos de los que se aplican a otros tipos de ayuda. Se trata del principio de humanidad (según el cual todas las víctimas de catástrofes deben ser tratadas humanamente con especial atención a las personas más vulnerables), del principio de neutralidad (se deben ayudar por igual todas la partes en un conflicto que precisen ayuda humanitaria), del principio de independencia (la ayuda humanitaria no puede perseguir ni objetivos ni principios con una finalidad política, militar o económica distinta de la acción exterior de la UE, los cuales se enumeran en el art. 21 del TuE de TdL), y del principio de imparcialidad y no discriminación (la ayuda humanitaria no podrá ser concedida siguiendo interés particular alguno). La primera frase del artículo 214.1. TFUE no puede afectar esta obligación legal. En suma, la incorporación de una disposición de un tratado específico sobre la ayuda humanitaria apoya la consolidación de las características particulares de acción de la UE en este campo; sin embargo, en la práctica, los límites a menudo son borrosos en otras áreas de política.

Por otra parte, la referencia a los principios y objetivos de la acción exterior de la UE en el artículo 214.1 del TFUE como una amenaza potencial a la independencia de las operaciones humanitarias, puede ser considerada como una llamada general a la coherencia en la UE ante la respuesta a emergencias globales. Aunque la ayuda humanitaria está sujeta a unas condiciones y principios específicos, lo que implica que es distinta de otras formas de ayuda, esta solo puede ser eficaz cuando se encuentra vinculada a otras políticas. Esta interpretación está en línea con el Consenso
Europeo de Desarrollo (European Union, 2008 , p. 3) que estableció que la ayuda humanitaria de la UE "debe tener en cuenta los objetivos de desarrollo a largo plazo" y "está estrechamente vinculada a la cooperación al desarrollo”. Además, en el artículo 214.4 del TFUE se establece que la UE será competente para "celebrar con los terceros países y con las organizaciones internacionales competentes cualquier acuerdo adecuado para la consecución de los objetivos enunciados en el apartado 1 y en el artículo 21 del Tratado de la Unión Europea" (Comunidades Europeas, 2010, p. 143). Este punto se complementa con el artículo 214.7 del TFUE, en el que se estipula que "la Unión velará por que sus acciones de ayuda humanitaria estén coordinadas y sean coherentes con las de las organizaciones y organismos internacionales, en particular los que forman parte del sistema de las Naciones Unidas" (p. 143).

La exigencia de armonización y de coordinación con las otras acciones y políticas exteriores de la UE (política de desarrollo, comercial, de seguridad y defensa) influye en las operaciones de ayuda humanitaria -lo que se menciona en el artículo 21.3 del TUE-, y se prevé el deber de la ue de hacer todo lo posible para mantener la coherencia entre las distintas facetas de su política exterior, así como entre su acción exterior y sus otras políticas (Comunidades Europeas, 2010, p. 29).

En este mismo sentido, el artículo 214.6 del TFue establece los principios de complementariedad y coordinación, tan importantes para la Unión (Comunidades Europeas, 2010, p. 143). De esta disposición se desprende que "la coordinación" mejorará la "eficiencia", 
así como la "complementariedad", y que la "coordinación" debe hacerse entre "acciones". Por tanto, parece que la "coordinación" hace referencia a los diferentes actores que toman decisiones, para que tengan una sola voz y adopten una misma posición. El TUE del TdL regula la coherencia vertical -de acuerdo con lo establecido en artículo 24.3 del TUE, "según el cual los Estados miembros apoyarán activamente y sin reservas la política exterior y de seguridad de la Unión, con espíritu de lealtad y solidaridad mutua y respetarán la acción de la Unión en este ámbito y se abstendrán de toda acción contraria a los intereses de la Unión o que pueda perjudicar su eficacia como fuerza de cohesión en las relaciones internacionales, y el Consejo y el Alto Representante velarán por que se respeten estos principios"-; y la coherencia horizontal -según lo establecido en artículo 21.3 del TUE- y financiera entre la Unión y los Estados miembros a la hora de responder ante las emergencias internas y externas -catástrofes naturales o provocadas por el hombre-, pero este hecho posibilita la instrumentalización y la politización de la ayuda humanitaria por parte de la política exterior.

Cabe señalar que la Alta Representante para Asuntos Exteriores y Política de Seguridad (que es uno de los vicepresidente de la Comisión) es la encargada de coordinar y dar coherencia a la actuación exterior de la UE, cuyas competencias están señaladas en los artículos 18.4 y 21.3 del TUE del TdL (Comunidades Europeas, 2010, p. 27). La responsabilidad de asumir la coherencia y la coordinación de la acción exterior de la UE es una tarea indispensable y compleja; antes quedaba en manos del Consejo y de la Comisión, y ahora se concentra y se ve asistida por el Servicio Europeo de Acción Exterior (SEAE), un nuevo órgano que está entre ambas instituciones.

En otras palabras, basado en el principio de coordinación, el artículo 214.6 del TFUE faculta a la Comisión a adoptar medidas para promover la coordinación entre la Unión y sus Estados miembros a fin de que puedan trabajar activamente y mejorar la eficacia de sus esfuerzos en el ámbito de la ayuda humanitaria.

En el caso de la ayuda humanitaria y de emergencia, es la Comisión Europea -y en particular la DG de ayuda humanitaria y gestión de la crisis $(\mathrm{ECHO})^{13}-$ la encargada de canalizar la ayuda. El principio de coordinación se aplica no solo a la relación de la Unión con sus Estados miembros, sino también en las relaciones de la Unión con las organizaciones especializadas de Naciones Unidas (ACNUR, UNICEF, OMS, Оснан) (Comunidades Europeas, 2010,

13 La Oficina de Ayuda Humanitaria de la Comunidad Europea (всно) se creó en 1992 con el objetivo de prestar y coordinar la ayuda humanitaria de la UE; en el ańo 2004 pasó a formar parte de la Comisión Europea y a ser una DG de dicha Comisión, aunque conservó las siglas de su anterior nombre. A partir del ańo 2010 incluye la protección civil con el objetivo de coordinar y dar respuesta a las catástrofes tanto dentro como fuera de la Unión. Sus principales objetivos son facilitar y gestionar fondos, comprobar la buena gestión de las finanzas y velar por que los bienes y servicios de sus socios lleguen a las poblaciones afectadas de forma eficaz y rápida, y que manera que respondan a necesidades reales. 
p. 143), y organizaciones internacionales no gubernamentales de ayuda humanitaria tales como el Comité Internacional de la Cruz Roja (CICR), Oxfam, Médicos Sin Fronteras, entre otras (art. 220 del TFUE).

La ayuda humanitaria de la Unión se canaliza por medio de la DG EcHo que colabora con las Naciones Unidas, pero no ejecuta programas de asistencia humanitaria, sino que financia acciones $\mathrm{u}$ operaciones que realizan sus socios. Además de la EcHO, la Unión cuenta con otros dos mecanismos para apoyar y coordinar la ayuda de urgencia con la de los Estados miembros: a) el Mecanismo de Protección Civil de la Unión ${ }^{14}$, que cuenta con cuatro instrumentos: I) Capacidad Europea de Respuesta a Emergencia ${ }^{15}$, conocida como fondo común voluntario-; II) el Centro de Coordinación de la Respuesta a Emergencias, conocido como Centro de Coordinación; III) el Sistema Común de Comunicación e
Información de Emergencia, y IV) el Cuerpo Médico Europeo ${ }^{16}$. b) El Cuerpo Voluntario Europeo de Ayuda Humanitaria.

La aplicación de los principios de derecho internacional humanitario en las acciones de la DG ECHO no ha quedado bien establecida cuando la UE actúa en los dos ámbitos sobre el terreno, al existir riesgo de contaminación con intereses de naturaleza política.

A pesar de ello, no cabe duda de que el nuevo marco normativo e institucional pueda garantizar la coherencia-vertical, horizontal y financiera- entre la uE y los Estados miembros cuando responden a las emergencias internas y externas; pero también puede darse la instrumentalización y la politización de la ayuda humanitaria ${ }^{17}$.

Por otra parte, cuando los Estados miembros de la Unión utilizan sus competencias en el ámbito de la ayuda humanitaria están sujetos al principio de cooperación leal vis-à-vis

14 Creado en aplicación de la Decisión 1313/2013/ue del Parlamento y del Consejo, del 17 de diciembre de 2013, relativo al Mecanismo de Protección Civil de la Unión (Do L 347 de 20.12.2013, p. 924). Según lo establecido en el artículo 1, el MPCU tiene como objetivo "reforzar la cooperación entre la Unión y los Estados miembros y facilitar la coordinación en el ámbito de la protección civil con el objetivo de mejorar la eficacia de los sistemas de prevención, preparación y respuesta ante catástrofes naturales o de origen humano" (p. 928).

15 Creado en mayo de 2013, dentro de ECHO, como sucesor del Centro de Control de Información (cCI), es el centro operativo del MPCUE, en el que se unen una serie de equipos y material de socorro comprometidos previamente para su despliegue durante las operaciones de respuesta de emergencia en todo el mundo.

16 Creado en febrero de 2016 con la finalidad de contribuir a la movilización de equipos especializados en medición y salud pública, así como de material de emergencia dentro y fuera de la UE. Los Estados miembros de la Unión y otros países europeos que participan en el sistema ofrecen material y equipos médicos para que pueda desplegarse rápidamente antes de que ocurra alguna emergencia.

17 La politización de la ayuda humanitaria no es un fenómeno nuevo; en los últimos años se han presentado varios casos en los que se ha dado dicha politización. En República Democrática del Congo, Afganistán, Haití, Libia, Siria, y en otros lugares del mundo, la ayuda humanitaria se ha visto condicionada por la agenda política. Uno de los últimos casos es Siria, en donde no se cumplen los principios humanitarios en el conflicto. La ayuda humanitaria debe ofrecerse a todos por igual -grupos sociales, étnicos y religiosos-. 
de la UE. El artículo 214 TFUE establece la base jurídica de la política de ayuda humanitaria propuesta por la Comisión ("reglamentos") que debe negociarse con el Consejo y el Parlamento, y someterse a la aprobación de ambos, de conformidad con el procedimiento legislativo ordinario de la uE. Las medidas de ejecución de la Comisión (“decisiones") también se presentan al Parlamento Europeo, que tiene competencias de supervisión ${ }^{18}$, es decir, que con el fin de establecer las normas específicas para la adopción de decisiones respecto a las operaciones de ayuda humanitaria, es necesario primero adoptar una legislación en la que se establezca cómo se adoptarán estas decisiones (art. 214.3 del Tfue) (Comunidades Europeas, 2010, p. 143).

Hay que señalar que el TdL introdujo varias innovaciones para aumentar la coherencia de la acción exterior de la UE. La primera innovación que estableció fue la inclusión de una lista general de los objetivos de la "Acción Exterior de la UE" en el artículo 21.1 del TUE. Siguiendo la aplicación horizontal de este artículo, el objetivo "para ayudar a las poblaciones, países y regiones que se enfrenten a catástrofes naturales o hechos por el hombre" no se refiere exclusivamente a la política de ayuda humanitaria de la UE, pero puede, en principio, también ser ejercitada sobre la base de otras políticas de la Unión. En segundo lugar, están las nuevas estructuras institucionales creadas y sus funciones, en particular el SEAE y el Alto Representante de la Unión para Asuntos Exteriores y Política de Seguridad. Al contrario de la cooperación al desarrollo, la ayuda humanitaria no cae bajo la competencia del SEAE. La CE, y en particular la DG ECHO de ayuda humanitaria y protección civil, son las encargadas de facilitar la coordinación con y entre los Estados miembros de la UE en la acción humanitaria y política, con el fin de aumentar su eficiencia y la complementariedad.

Una mayor coherencia y coordinación entre la Unión y los Estados miembros en respuesta a una catástrofe o crisis prolongada es una cuestión fundamental para mejorar la eficacia de la contribución global de la UE a la ayuda. Desde 2009, la coordinación con los Estados miembros se realiza con el Grupo de Trabajo del Consejo sobre Ayuda Humanitaria y Ayuda Alimentaria (COHAFA), del que forma parte la Comisión. A nivel estratégico, el COHAFA contribuye significativamente a la coherencia y complementariedad de las actividades de ayuda humanitaria de la UE y sus Estados miembros. A pesar de ello, existe

18 En el Parlamento Europeo, la ayuda humanitaria entra dentro del ámbito de competencias de la Comisión de Desarrollo (DEve), y la protección civil es incumbencia de la Comisión de Medio Ambiente, Salud Pública y Seguridad Alimentaria (ENVI). Además, el Parlamento controla la prestación de la ayuda humanitaria y vela por que las disposiciones presupuestarias se ajusten a las necesidades humanitarias. La Comisión Deve, como el Parlamento en general, también ha procurado influir en las decisiones estratégicas y las orientaciones políticas de la Comisión mediante opiniones y resoluciones, incluidos los informes de iniciativa propia. El Parlamento evalúa el programa anual de trabajo de la Comisión y la estrategia operativa de la DG ECHO, además de invitar periódicamente al comisario a intercambiar puntos de vista con la Comisión Deve. 
un temor generalizado entre la comunidad (Oxfam, 2012) y la DG есно (Georgieva, 2011a) por la incorporación de la ayuda humanitaria comunitaria como una política más de la acción exterior de la UE en virtud del TdL, y como una interpretación más amplia de la función de coordinación de la SEAE, que puede llevar a la politización de la entrega.

Esta preocupación es resultado de la aspiración de la UE de tener mayor visibilidad, y de introducir el objetivo de la coherencia mejorada para, de esta manera, fortalecer su acción exterior. La falta de conocimiento y visibilidad de las actividades exteriores de la UE preocupa a los políticos en Bruselas. Esto también aplica a las acciones humanitarias que a menudo pasan desapercibidas para la opinión pública, tanto de la UE como de los países receptores. Sin embargo, en el caso de la ayuda humanitaria, una mayor visibilidad puede entrar en conflicto con el imperativo humanitario de proporcionar ayuda a partir del enfoque basado en las necesidades, lo que puede afectar la independencia política, económica y militar, u otros objetivos.

Quizás la aportación más original para dar mayor visibilidad a las actividades de la UE ha sido la creación del Cuerpo Voluntario Europeo de Ayuda Humanitaria (CVEAH), establecido en el artículo 214.5 del true. En él se propone la creación de un CVEAH para promover la incorporación de jóvenes europeos a la ayuda humanitaria. Prevé que el Consejo y el Parlamento Europeo, mediante el procedimiento legislativo ordinario, adopten los reglamentos, el estatuto y las normas de funcionamiento del Cuerpo que nace con el desafío de establecer "un marco para que los jó- venes europeos puedan aportar contribuciones comunes a las acciones de ayuda humanitaria de la Unión". Para ello, la Comisión propuso una asignación de 210 millones de euros para el CVEAH, en el próximo marco financiero plurianual para el periodo 2014-2020.

En un primer momento, los agentes y las organizaciones humanitarias rechazaron esta iniciativa que tenía difícil encaje, con un sector donde la necesidad de profesionalización es tan alta. Entonces ¡cómo enlazar los principios humanitarios, el desarrollo de actividades de voluntariado en situaciones de emergencia con la necesidad de contar con un nivel de preparación profesional para ello? Esta fue la primera cuestión que planteó la posibilidad de crear un cuerpo de voluntariado comunitario en ayuda humanitaria.

Esta propuesta planteó dudas en la comunidad acerca de las implicaciones que podría tener esta iniciativa sobre la independencia de la ayuda humanitaria de la UE (Schick, 2013). El CVEAH es una oportunidad para proponer estándares europeos de voluntariado en el tema. Las acciones del cuerpo se realizarán de conformidad con los principios de la ayuda humanitaria: humanidad, neutralidad, imparcialidad e independencia. La Comisión propuso desarrollar las normas europeas de gestión del voluntariado para los proyectos humanitarios, $\mathrm{y}$ un programa de formación para preparar a los voluntarios antes de pasar a la acción, y ser enviados como "voluntarios de ayuda humanitaria de la UE" en proyectos de cooperación con las organizaciones internacionales humanitarias (gubernamentales y no gubernamentales). 
El Reglamento (UE) 375/2014, de 3 de abril de 2014 (Unión Europea, 2014), por el que se creó el CVEAH, estableció un marco legal para las contribuciones conjuntas de los voluntarios europeos en apoyo y complemento de la ayuda humanitaria en terceros países. Tiene como objeto "reforzar la capacidad de la Unión para prestar ayuda humanitaria basada en las necesidades con el fin de preservar la vida, prevenir y aliviar el sufrimiento humano y salvaguardar la dignidad humana” (p. 2), así como "reforzar la capacidad y la resistencia de las comunidades vulnerables o afectadas por catástrofes en terceros países, concretamente mediante la preparación para casos de catástrofe, la reducción de los riesgos de catástrofe y el refuerzo del vínculo entre la ayuda de emergencia, la rehabilitación y el desarrollo" (p. 2).

El Reglamento (UE) 375/2014 intenta aumentar la capacidad de la UE para responder a las necesidades de ayuda humanitaria y a las acciones humanitarias mejorando la coordinación y coherencia con el voluntariado de los Estados miembros, evitando el solapamiento entre la ayuda humanitaria, las acciones de emergencia y con otras políticas e instrumentos de la Unión.

Hay que señalar que mientras que el TdL ha fortalecido la independencia de la ayuda humanitaria de la UE, la búsqueda de coherencia es vista como un desafío para el logro de una ayuda basada en necesidades. Para examinar este hecho procedemos a hacer un análisis más en profundidad de cómo la UE trata de conciliar los objetivos políticos de aumentar la coherencia y la independencia en la práctica. A partir del análisis de documentos oficiales y textos jurídicos, nos centraremos en analizar la relación de ayuda humanitaria con otras políticas de la acción exterior de la Ue, a saber, la Política de Desarrollo, la Política Exterior de Seguridad Común -en particular la Gestión de Crisis- y la Política Comercial Común.

\section{ARTICULACIÓN DE LA AYUDA HUMANITARIA Y LAS OPERACIONES DE GESTIÓN DE CRISIS EN LA UNIÓN EUROPEA}

Sobre la base de la disposición específica dedicada a la ayuda humanitaria de la uE en el TdL, se deduce que esta no puede ser utilizada como una herramienta para para apoyar las operaciones de gestión de crisis de la PESC. El Consenso Europeo estableció que "la ayuda humanitaria de la UE no es una herramienta de gestión de crisis" (European Union, 2008, p. 2). El artículo 40 TuE del TdL es una garantía adicional para la independencia de la ayuda humanitaria de la Unión en relación con el potencial de la política exterior y las influencias militares. De acuerdo con esta disposición, la aplicación de medidas de la PESC no puede afectar la aplicación de los procedimientos y el alcance de las competencias de las instituciones en virtud de la acción no PESC de la uE y viceversa.

En el TdL, la ayuda está vinculada a la PESD, según lo establecido en el artículo 43.1 y 2 del tue (Comunidades Europeas, 2010, p. 39), incluidas disposiciones en materia de desarme y operaciones humanitarias y de prevención de conflictos, entre otras. Según lo establecido en el artículo 43 del TuE del TdL, la Unión puede recurrir a medios civiles y militares para perseguir tareas humanitarias, 
mientras que el Consenso Europeo sostiene que el uso de recursos de protección civil en situaciones de emergencia debe ser una excepción (European Union, 2008, p. 7). Bajo ciertas circunstancias, las medidas adoptadas en el contexto de la PCSD de la UE pueden usarse para apoyar las operaciones humanitarias. Esto está en relación con la aplicación horizontal del artículo 21.2 (g) "ayudar a las poblaciones, países y regiones que se enfrenten a catástrofes naturales o de origen humano" (Comunidades Europeas, 2010, p. 29). Sin embargo, el uso de instrumentos de la PCSD en el contexto de las operaciones humanitarias sigue siendo controvertido. Este es particularmente el caso de los desastres provocados por el hombre, debido a su dimensión política inherente. Del mismo modo, se establece que los medios y las capacidades militares en apoyo de las operaciones de ayuda humanitaria deben ser "utilizados solo en circunstancias muy limitadas como un último recurso". El respeto por el DIH exige que las operaciones militares de la UE de apoyo a la asistencia humanitaria estén sujetas a condiciones estrictas. Por ejemplo, este tipo de operaciones solo se pueden realizar a petición de la OCAH y cuando todas las alternativas civiles hayan sido exploradas y agotadas. Fundamentalmente, los activos militares utilizados en este escenario deben permanecer bajo la coordinación civil y deben respetar el enfoque basado en las necesidades y la naturaleza neutral de la ayuda humanitaria. En otras palabras, el imperativo humanitario tiene que ser respetado en todas las circunstancias.

La DG ECHO considera que una coordinación eficaz entre las esferas civil y militar es esencial para promover el respeto de los principios humanitarios, y en 2014 y 2015 intensificó la coordinación con el personal militar de la UE. Ejemplo de ello es la misión PCSD de la UE destinada a la mejora de la seguridad general en Bangui (EUfOR RCA) ${ }^{19}$, que se inició en febrero de 2014, pero la DG ECHO mantenía contactos sistemáticos con sus homólogos del SEAE desde el inicio del proceso de planificación. Se seguía así el enfoque integral de la ue de cara a los conflictos y las crisis, lo que permitió que los militares comprendieran bien las cuestiones humanitarias y respetaran el modus operandi de la ayuda.

Otro ejemplo reciente que ilustra el desafío de coordinar la gestión de crisis y la asistencia humanitaria es la respuesta de la UE ante el conflicto de Siria (van Elsunwege y Orbie, 2014, pp. 20-45). El 24 de junio de 2013, la Comisión Europea y la Alta Representante anunciaron conjuntamente "un enfoque global de la UE a la crisis Siria" ${ }^{20}$. La respuesta global de la uE tiene varios objetivos, que incluyen la facilitación de una solución política a la crisis, la prevención de la desestabilización regional y la oferta de asistencia humanitaria. Como tal, la ayuda humanitaria es parte integrante de una estrategia más amplia de la uE para hacer frente a la situación de crisis en Siria. Podría decirse que este enfoque
19

20

Operación militar de la Unión Europea en la República Centroafricana.

Comisión Europea y Alta Representante de la ue para Asuntos Exteriores y Política de Seguridad, 2013. 
conlleva el riesgo de que la ayuda financiada por la Unión se perciba como un instrumento de política exterior (Pontiroli, Ponthieu y Derderian, 2013), ya que puede vincularse con las sanciones contra el régimen de Bashar Al Assad en Siria. La petición de más ayuda a Siria vino de los ministros de Asuntos Exteriores de la Unión, en la misma sesión en que se decidió que las sanciones contra el Gobierno sirio fueran más estrictas. Para responder a las necesidades humanitarias de la población civil siria, los Estados miembros de la UE podrán autorizar la venta, el suministro o la transferencia de equipos y tecnología clave para los sectores estratégicos (petróleo y gas, y la banca) en Siria. Esto solo es posible bajo ciertas condiciones, como la consulta previa con la Coalición Nacional Siria de Oposición y Fuerzas Revolucionarias (Council of the eu, 2013b). La Comisión Europea anunció, el 15 de marzo de este año, que invertiría 445 millones de euros en ayuda humanitaria dirigida a atender la crisis siria -la peor crisis humanitaria desde la Segunda Guerra Mundial, según palabras del Comisario de Ayuda Humanitaria y Gestión de Crisis, Christos Stylianides-, de los cuales 140 millones de euros financiarán proyectos en ese país, otros 165 millones serán invertidos en Turquía, 87 millones en Líbano y 53 millones en Jordania (El financiero, 2016).

\section{ARTICULACIÓN DE LA AYUDA HUMANITARIA CON LA POLÍTICA DE COOPERACIÓN AL DESARROLLO}

Las políticas de cooperación y ayuda a desarrollo de la $\mathrm{UE}^{21}$ han ido cambiando sus enfoques y prácticas en la última década. La UE se ha convertido en uno de los actores más importantes del sistema internacional de cooperación y ayuda al desarrollo. En 2013, la ayuda oficial al desarrollo (AOD) colectiva de la ue (instituciones y sus EEMM) fue de 58.200 millones de dólares (Comisión Europea, 2015b). En 2014, la AOD colectiva fue de 59.000 millones de euros (un 2,4\% más que en 2013), y en 2015 esta ascendió a 68.000 millones de euros (un 15\% más respecto al año anterior) (Comunidades Europeas, 2010, p. 143).

Como la ayuda humanitaria y la cooperación para el desarrollo están estrechamente vinculadas, a menudo es difícil trazar una frontera exacta entre la asistencia ad hoc en virtud del artículo 214 del TFue (Comunidades Europeas, 2010, p. 141) y la ayuda estructural en virtud del artículo 208 del tFue (p. 141). El objetivo principal de la política de cooperación para el desarrollo es la reducción y, a largo plazo, la erradicación de la pobreza ${ }^{22}$, como se establece en el artículo 21 del TUE

\footnotetext{
21 Son muchos los estudiosos y la bibliografía sobre la política de desarrollo de la UE; algunos de ellos son los siguientes: Cox (2000), Grasa (2001), Barbé (2000 pp. 55-82), Gómez-Galán y Sanahuja (2001), Lancaster (2006), Edwards (2002), Fuentetaja Pastor (2005, pp. 81 y ss.), González Alonso (2000, pp. 439 y ss.), Navarro González (1994, p. 9 y ss.), Fuentetaja Pastor (2005, pp. 163-196), Corral Suárez (2010, pp. 201-227).

22 Este es el primero de los Objetivos de Desarrollo del Milenio, con el que se pretendía que en el año 2015 se hubiera reducido a la mitad el número de personas que pasan hambre en el mundo y el número de personas que viven con menos de un dólar diario.
} 
(Comunidades Europeas, 2010, pp. 28-29) y en el artículo 208 del true (p. 141).

Con el fin de abordar esta cuestión, la Comisión Europea se adelantó e introdujo un enfoque integral entre la ayuda humanitaria y el desarrollo. Este enfoque permite vincular la ayuda de emergencia, la rehabilitación y el desarrollo (VARD). Sin embargo, la aplicación del concepto VARD no siempre ha sido fácil; lo mismo pasa con el establecimiento de uniones entre la DG ECHO y la DG DEVCO (desarrollo y cooperación) en la "zona gris" de la rehabilitación (Versluys, 2008a, p. 105). Esto es debido a los diferentes puntos de vista entre el desarrollo y los actores humanitarios dentro de la UE, así como a los obstáculos institucionales y operativos (Morazán, Grünewald, Knoke y Schäfer, 2012, p. 18). En 2003, se estableció un grupo interservicios sobre la transición para seguir un enfoque más coherente, presidido conjuntamente por la DG ECHO y la DG DEVCO. En la práctica, sin embargo, este grupo no ha dado grandes resultados (Versluys, 2008b, pp. 91-116), ya que la ayuda humanitaria de la UE convive con otras acciones que se desarrollan en los ámbitos de la protección civil y la cooperación al desarrollo, así como con otros instrumentos como el de la estabilidad, el de militares o de defensa civil vinculadas a la PESC y a la PECSD (Comunidades Europeas, 2000).

La experiencia de misiones sobre el terreno revela, además, que VARD sigue siendo un desafío para la UE. Un ejemplo concreto fue la respuesta de la Unión al terremoto de Haití de 2010; al mismo tiempo que mostró ser un proveedor rápido y generoso de la ayuda de emergencia, se encontró con varios problemas en la entrega de asistencia para la transición hacia el desarrollo a largo plazo (Werleigh y Brouwer, 2011), dado que hubo un considerable déficit de financiación entre este y el alivio a corto plazo. El Grupo de Trabajo sobre Haití se establecido después del terremoto para hacer frente a la gestión de crisis ad hoc, "creando más competencia y luchas de poder entre la Comisión y el SEAE y más retrasos que resultados concretos" (Morazán, Grünewald, Knoke y Schäfer, 2012, p. 18).

La UE ha tomado recientemente algunas iniciativas prometedoras en el ámbito de la VARD, tales como los programas de pilotaje en el Cuerno de África (Apoyo Cuerno de África Resiliencia). Sin embargo, después de casi veinte años de la primera comunicación de la Comisión sobre vard, solo se puede decir que el concepto nunca se ha puesto en práctica más allá de algunos proyectos piloto (Hauck, 2012). Tanto el comisario de Desarrollo, Piebalgs (2011), como la comisaria de la Ayuda Humanitaria, Georgievas (2011b), admitieron que el enfoque de la UE para VARD podría mejorarse, por ejemplo, creando instrumentos de financiamiento más flexibles. En resumen, si bien VARD no afecta la independencia de la entrega de ayuda humanitaria, como un instrumento para lograr la coherencia entre la ayuda humanitaria y la cooperación al desarrollo, se ha perdido hasta ahora su objetivo.

Una reciente iniciativa de la UE relativa a la unión de la ayuda al desarrollo y humanitaria es la Comunicación de la Comisión sobre la resiliencia (Benadusi, 2014, pp. 174-183). La resiliencia se define como "la capacidad de un individuo, una familia, una comunidad, un país o una región para resistir, adaptarse 
y recuperarse rápidamente de las tensiones y choques" (European Commission, 2012b, p. 5). Como tal, se requiere un enfoque integral que incluya herramientas de evaluación de riesgos, un enfoque en la prevención y preparación, y una respuesta mejorada a las crisis. Una política basada en la mejora de la capacidad de recuperación implica que los donantes no solo intervienen para hacer frente a las consecuencias de las crisis de emergencia, sino también a las causas profundas de las crisis recurrentes (p. 2). Al necesitarse un enfoque coherente entre la ayuda humanitaria y la asistencia para el desarrollo, el concepto de resiliencia ha sido central en los debates sobre la mejora de la política de la UE VARD.

\section{ARTICULACIÓN DE LA AYUDA HUMANITARIA Y LA POLÍTICA COMERCIAL COMÚN}

Respecto a la política comercial común de la UE, el TdL, en el artículo 207.1 del true estipula que esta "se llevará a cabo en el marco de los principios y objetivos de la acción exterior de la Unión" (Comunidades Europeas, 2010, p. 140). Teniendo en cuenta que se ha puesto mucha atención a la coherencia de la política comercial de la Ue con sus objetivos de desarrollo, no hay muchos casos en que la Unión utilice deliberadamente sus instrumentos comerciales como respuesta a las crisis humanitarias. Un caso concreto para explorar la articulación de la ayuda humanitaria y el comercio es la respuesta de la UE a las inundaciones monzónicas de 2010 en Pakistán. El Consejo Europeo pidió apoyo para la adopción de medidas comerciales preferenciales autónomas excepcionales con carácter urgente, y el suministro de ayuda humanitaria para la recuperación de Pakistán. Se acordó "conceder exclusivamente a Pakistán aumento del acceso al mercado de la UE a través de la reducción limitada inmediata y el tiempo de las importaciones clave de Pakistán" (European Council, 2010, p. 10). La decisión del Consejo Europeo de utilizar un instrumento de política comercial para el logro de un objetivo humanitario estaba en plena consonancia con la lógica del artículo 21 del tue de Lisboa para aumentar la coherencia de la acción exterior de la UE. Sin embargo, la iniciativa enfrenta obstáculos legales y políticos significativos, ya que se trata de preferencias excepcionales que no son compatibles con el principio de no discriminación positiva ni negativa de la Organización Mundial del Comercio (омc), era necesario obtener una exención de esta organización antes de otorgar dichas preferencias comerciales.

Varios miembros del Parlamento Europeo, así como las industrias de importación sensibles procedentes de Francia, Italia, Portugal y Espańa cuestionaron la conveniencia de tal medida. En particular, expresaron su preocupación por las implicaciones económicas para los textiles y la industria del etanol de la UE, y la ausencia de cualquier condicionalidad política en la propuesta de la Comisión, ya que al igual del SPG, está sujeto a la cláusula democrática (European Parliament, 2011). Dada la inspiración humanitaria de la iniciativa comercial, este último punto es sorprendente, ya que socavaría el principio humanitario de la independencia, según la cual la ayuda a las personas necesitadas no puede estar sujeta a las condiciones políticas, económicas o milita- 
res. La medida fue adoptada en el marco de la política comercial común (PCC) de la Unión, según lo establecido en el artículo 207.2 del TFUE, y no como parte de la ayuda humanitaria de la UE en virtud del artículo 214 del mismo instrumento. Por tanto, los principios humanitarios establecidos en el artículo 214.2 del TFUE se reflejan en el Consenso Europeo y no se aplican automáticamente a este tipo de medidas. En el contexto de la PCC, la concesión de preferencias comerciales puede estar condicionada al respeto de los derechos fundamentales ${ }^{23}$. Por ello no es sorprendente que el PE solo aceptara la propuesta de reglamento después de la inclusión de disposiciones explícitas de condicionalidad. De acuerdo con el Reglamento, Pakistán solo tiene derecho a beneficiarse de los acuerdos preferenciales si no se involucra en "violaciones graves y sistemáticas de los derechos humanos, incluidos los derechos laborales fundamentales, los principios fundamentales de la democracia y el Estado de derecho" (European Commission, 2012a, p. 43). Los miembros del Parlamento Europeo también insertaron un comunicado en el que manifestaron que la medida no es un precedente para la PCC de la UE, sino estrictamente una respuesta a la situación específica en Pakistán, lo que limita la aplicación coherente de las preferencias comerciales en el contexto de las catástrofes humanitarias.
Dado que la introducción unilateral de preferencias comerciales estaría violentando el principio de nación más favorecida (NMF) y los principios de no discriminación, la Unión tuvo que solicitar una exención (Bartels, 2007, pp. 865-886).

El caso de Pakistán demuestra que la PCC puede ser utilizada como un instrumento para promover los objetivos humanitarios a raíz de una emergencia mundial. Sin embargo, el contexto político más amplio, con la importancia geoestratégica de Pakistán, puede haber influido en la decisión. Este caso muestra los límites y desafíos que enfrenta la UE en la consecución del objetivo de una mayor coherencia entre sus políticas exteriores. La coherencia entre su política comercial y los objetivos de ayuda humanitaria es muy difícil de establecer, entre otras cosas, porque está estrechamente vinculada con los intereses económicos ${ }^{24}$.

\section{CONSIDERACIONES FINALES}

Como se ha podido observar, la ayuda humanitaria es parte de la acción exterior de la Unión Europea. El tdu le da su lugar como una política más de la acción exterior, con la que debe coordinar sus acciones sin perder su independencia y la coherencia con las diferentes gestiones de la Unión. El artículo 214 del TEU pone de relieve el compromiso de la UE

\footnotetext{
23 La concesión de preferencias comerciales, por razones relacionadas con la política exterior, puede no ser compatible con el derecho internacional económico, como quedó claro en el caso de las preferencias arancelarias de la CE (OMC), 2004.

24 Podemos citar algunos ejemplos de incoherencia de políticas entre la ayuda humanitaria y la política comercial común, tales como la concesión de preferencias comerciales autónomas en la política comercial de la uE, que se hace en casos excepcionales, o el establecimiento de sanciones económicas.
} 
de prestar ayuda humanitaria consistente en asistencia, socorro y protección a las víctimas de catástrofes naturales o de origen humano en todo el mundo.

La ayuda humanitaria solo puede ser eficaz cuando es independiente y está vinculada a las políticas de acción exterior. La Unión, al responder a las emergencias internacionales, tiene que garantizar la coherencia entre la ayuda humanitaria y las otras políticas de la acción exterior, hecho que puede socavar la independencia de dicha ayuda, al intentar establecer sinergias positivas con las demás políticas exteriores, debido: a) obstáculos institucionales y políticos, b) limitaciones legales, c) incompatibilidades operacionales.

Desde la década del 2000, la UE ha reclamado la independencia de la ayuda humanitaria, ha desarrollado capacidades militares y se ha perfilado como un actor principal en la ayuda al desarrollo. La UE también ha seguido una política de comercio internacional proactiva y ha expresado explícitamente su ambición de ser un actor de coherencia en la escena mundial. El Consenso Europeo de Ayuda Humanitaria y el $\mathrm{TdL}$ conforman el marco político y jurídico para implementar la política de ayuda humanitaria comunitaria, que es complementaria a la de los 28 Estados miembros.

En estas páginas se han podido observar los cambios que se han dado en la ayuda humanitaria de la UE a partir del TdL; la toma de decisiones en este ámbito se realiza en la Comisión y, en particular, en la DG ECHO, y la coordinación con el SEAE parece que no ha socavado el papel fundamental de la ayuda y de los principios humanitarios (OECD-DAC,
2012, pp. 90-95), aunque la búsqueda de coherencia en sus acciones sí ha planteado desafíos a esta política. La tendencia hacia un enfoque más integral para la gestión de crisis, incluyendo una función de coordinación más activa para el SEAE, puede dar lugar a nuevas resistencias institucionales con la DG ECHo. De ahí la necesidad de clarificar la división de responsabilidades de cada uno de los actores involucrados en las diferentes acciones de ayuda humanitaria y gestión de crisis para garantizar una cooperación eficaz sobre el terreno. Así mismo, hay que señalar que no se han obtenido avances prácticos en la vinculación de la ayuda de emergencia, rehabilitación y desarrollo.

Por último, parece ser que la uE es un actor clave a la hora de proporcionar y coordinar la asistencia humanitaria, pero permanecen las dificultades en cuanto a la integración de los programas en las estrategias más integrales de respuesta a desastres. Mientras que la independencia de la entrega de la ayuda no ha sido socavada hasta el momento, la UE experimenta dificultades para establecer sinergias positivas entre las respectivas políticas exteriores debido a obstáculos institucionales y restricciones legales, así como a los obstáculos políticos e incompatibilidades operacionales.

\section{REFERENCIAS}

Barbé, E. (coord.) (2000). Politica exterior europea. Barcelona: Ariel.

Bartels, L. (2007). The wTo legality of the EU's GSP + arrangement. Journal of International Economic Law, 10 (4), 865-886. 
Benadusi, M. (2014). Pedagogies of the Unknown: Unpacking "culture" in disaster risk reduction education. Journal of Contingencies and Crisis Management, 22 (3), 174-183.

Cideal Lancaster, C. (2006). Foreign Aid. Diplomacy, Development, Domestic Policies. Chicago: Chicago University Press.

Comisión Europea (2011). Informe anual de la Unión Europea sobre la ayuda humanitaria y las politicas de protección civil y su aplicación en 2010. сом (2011) 343 final. Recuperado de http:// ec.europa.eu/transparency/regdoc/rep/1/2011/ Es/1-2011-343-Es-F1-1.Pdf

Comisión Europea (2012). Informe anual de la Unión Europea sobre la ayuda humanitaria y las políticas de protección civil y su aplicación en 2011. сом (2012) 489 final. Recuperado de www.ipex.eu/ IPEXL-WEB/dossier/files/.../082dbcc53995d4e1 01399afe34ad012a.do

Comisión Europea (2012). El planteamiento de la UE sobre la resiliencia: aprendiendo de las crisis alimentarias. сом (2012) 0586 final.

Comisión Europea (2013). Informe anual sobre las políticas de ayuda humanitaria y de protección civil de la Unión Europea y su aplicación en 2012. сом (2013) 658 final. Recuperado de http:// ec.europa.eu/transparency/regdoc/rep/1/2013/ Es/1-2013-658-Es-F1-1.Pdf

Comisión Europea (2014). Marco de Acción de Hyogo posterior a 2015: gestionar los riesgos para lograr la resiliencia. сом (2014) 216 final.

Comisión Europea (2014). Informe anual sobre las políticas de ayuda humanitaria y de protección civil de la Unión Europea y su aplicación en 2013. сом (2014) 537 final. Recuperado de lineahttp://ec.europa.eu/transparency/regdoc/ rep/1/2014/es/1-2014-537-Es-F1-1.pDF
Comisión Europea (2015). Informe anual sobre las políticas de ayuda humanitaria y de protección civil de la Unión Europea y su aplicación en 2014. сом (2015) 406 final. Recuperado de http:// ec.europa.eu/echo/files/media/publications/annual_report/2014/COM_20linea 15_406_es.PDF Comisión Europea (2015). La Comisión Europea hace un llamamiento en favor de compromisos renovados para alcanzar los objetivos de la ayuda oficial al desarrollo [comunicado de prensa]. Recuperado de http://europa.eu/rapid/pressrelease_IP-15-4747_es.htm

Comunidades Europeas (2010). Versiones consolidadas del Tratado de la Unión Europea y del Tratado de Funcionamiento de la Unión Europea. Diario Oficial de la Unión Europea C 83/1.

Comunidades Europeas (2004). Tratado por el que se establece una Constitución para Europa. Diario Oficial de la Unión Europea Do c 310.

Comunidades Europeas (2000). La política de desarrollo comunitaria. сом 212 final.

Council of the European Union (1996). Regulation (EC), 1257/96 of 20 June 1996 on humanitarian aid. Official Journal of the European Union L 163.

Council of the European Union (2013a). Press Release PRESSE 339 PR CO 41, 3254th Council meeting, Foreign Affairs, 12584/13, 22 July.

Council of the European Union (2013b). Council Decision 2013/255/CFSP of 31 May 2013 concerning restrictive measures against Syria. Official Journal of the European Union L 147/14.

Corral Suárez, M. (2010). La cooperación al desarrollo: nuevos horizontes. Revista de Derecho de la Unión Europea, (18), 201-227.

Cox, A. et al. (2000). European development cooperation and the poor. Basingstoke: Macmillan/Overseas Development Institute. 
Dashwood, A. (2011). Conflicts of Competence in Responding to Global Emergencies. En Antoniadis, A., Schütze, R. y Spaventa, E. (eds.). The European Union and Global Emergencies. A Law and Policy Analysis, Hart (pp. 33-48). Oxford: Oxford

Edwards, M. 1. (2002). Futuro en positivo. La cooperación internacional en el siglo xxi. Intermón Oxfam.

El Financiero (2016). uE destinará 494 mdd en ayuda a crisis humanitaria en Siria. Recuperado de http:// www.elfinanciero.com.mx/mundo/ue-destinara494-mdd-en-ayuda-a-crisis-humanitaria-ensiria.html

European Commission (1996). Communication on Linking Relief, Rehabilitation and Development (LRRD). СОМ (96) 153 final.

European Commission (2001). Communication on Linking Relief, Rehabilitation and Development-An assessment. Сом (2001) 153 final.

European Commission (2010). Proposal for a regulation introducing emergency autonomous trade preferences for Pakistan. Сом (2010) 552 final.

European Commission (2012a). Proposal for a Regulation of the European Parliament and of the Council Establishing the European Voluntary Humanitarian Aid Corps. сом (2012) 514.

European Commission (2012b). The Eu Approach to Resilience: Learning from Food Security Crises. сом (2012) 586.

European Commission and High Representative of the Eu for Foreign Affairs and Security Policy (2013). Towards a Comprehensive Eu Approach to the Syrian Crisis. JOIN 22.

European Council (2010). European Council Conclusions, Annex II, Declaration on Pakistan, EUCO/21/1/10 REV 1.

European Parliament (2011). Debate on emergency autonomous trade preferences for Pakistan, 9 May 2011.
European Union (2008). European Consensus on Humanitarian Aid. Joint Statement by the Council and the Representatives of the Governments of the Member States meeting within the Council, the European Parliament and the European Commission. Official Journal of the European Union C 25.

European Union (2012). Regulation 1029/2012 of the European Parliament and of the Council of 25 October 2012 introducing emergency trade preferences for Pakistan. Official Journal of the European Union oJ L 316.

Fride, European Think-Tanks Group (2010). Nuevos desafios, un nuevo comienzo: próximos pasos en la cooperación al desarrollo europea. Recuperado de http://www.fride.org/publicacion/721/losproximos-pasos-en-la-cooperacion-europea-aldesarrollo.

Fuentetaja Pastor, J. A (2005). Política comunitaria de cooperación al desarrollo. Revista de Derecho de la Unión Europea, 9, 163-196.

Gauttier, P. (2004). Horizontal coherence and the external competencies of the European Union. European Law Journal, 10 (2), 23-41.

Gebhard, C. (2011). Coherence. En Hill, C. y Smith, M. (eds.). International Relations and the European Union (2 ed., pp. 101-127). Oxford: Oxford University Press.

Georgieva, K. (2011a). Helping People Together. Speech delivered at the Annual Conference of the European Commission's Humanitarian Aid Partners. Recuperado de http://europa.eu/rapid/ press-release_SPEECH-11-757_en.htm?locale=en Georgieva, K. (2011b). Policy Priorities - achievements and mapping the ways ahead. Speech delivered at the Development Committee of the European Parliament. 
Gómez-Galán, M. y Sanahuja, J. A. (coords.) (2001). La cooperación al desarrollo en un mundo en cambio. Madrid: Reflexiones desde nuevos ámbitos de intervención.

González Alonso, L. N. (2000). La política comunitaria de cooperación al desarrollo. En López Escudero, M. y Pérez Nanclares, J. M. Derecho comunitario material (pp. 439-453). Madrid: McGraw-Hill.

Grasa, R. (2000). La cooperación al desarrollo de la Comunidad Europea: naturaleza, mecanismos y políticas. En Barbé, E. (coord.). Política Exterior Europea (pp. 55-82). Barcelona: Ariel.

Hauck, V. (2012). What can bridge the divide between humanitarian aid and development? ECDPM Talking Point. Recuperado de http://ecdpm.org/ talking-points/bridge-divide-between-humanitarian-aid-and-development/

Khorana, S., Yeung, M. T., Kerr, W. A. y Perdikis, N. (2012). The battle over the eu's Proposed Humanitarian Trade Preferences for Pakistan: A Case study in multifaceted protectionism. Journal of World Trade, 46 (1), 33-60.

Koddenbrock, K. y Büttner, M. (2009). The will to bridge? European Commission and U.s. approaches to linking relief, rehabilitation and development. En Steets, J. y Hamilton, D. s. (eds.). Humanitarian Assistance. Improving U.S.European Cooperation (pp. 117-143). Baltimore: The Johns Hopkins University/Global Public Policy Institute. Recuperado de, http://www. gppi.net/fileadmin/gppi/Humanitarian_Assistance_Eu-Us-Cooperation.pdf

Morazán, P., Grünewald, F., Knoke, I. y Schäfer, T. (2012). Strengthening the link between Relief, Rehabilitation and Development (LRRD) in the EU'S Financing Instruments for Development and Humanitarian Aid under the MFF 2014-220. Study requested by the European Parliament's
Subcommittee on Security and Defence Committee on Development.

Navarro González, A. (1994). La política comunitaria de cooperación al desarrollo. Revista de Instituciones Europeas (1).

Nuttall, S. (2005). Coherence and Consistency. En Hill, C. y Smith, M. (eds). International Relations and the European Union (pp. 91-112). Oxford: Oxford University Press.

oeCD-DaC (2012). oecD Development Assistance Peer Reviews: European Union 2012. Paris: OECD-DAC. Oxfam (2012). Fit for purpose? The european external action service one year on. Briefing Paper.

Peterson, J. (2007). Eu Trade Policy as Foreign Policy. Biennial Conference of the European Union Studies Association (EUSA). Montreal. Recuperado de http://aei.pitt.edu/7998/1/peterson-j-10g.pdf

Piebalgs, A. (2011). Haiti, one year after: Keeping our promises and accelerating our efforts. Conference 'Haiti, One Year after the Earthquake', Brussels, Egmont Palace.

Pontiroli, A., Ponthieu, A. y Derderian, K. (2013). Losing principles in the search for coherence? A field-based viewpoint on the EU and humanitarian aid. The Journal of Humanitarian Assistance. Recuperado de http://sites.tufts.edu/jha/archives/ tag/comprehensive-approach

Portela, C. y Kolja, R. (2009). (In) Coherence in EU foreing policy: Exploring sources and remedies. Recuperado de http://aei.pitt.edu/33122/1/ portela._clara_(2).pdf

Rey, F. y Currea-Lugo, V. (2002), El debate humanitario: Madrid: Icaria.

Rey, F. (2005). El sistema internacional de respuesta a los desastres. Limitaciones y tendencias. Recerca, Revista de Pensamient Humanitarian, (I), pp 101126. Recuperado de http://www.e-revistes.uji.es/ index.php/recerca/article/download/240/222. 
Smith, M. E. (2004). The Quest for Coherence. En Sweet, A. S., Sandholdz, W. y Fligstein, N. (eds.). The Institutionalisation of Europe (pp. 171-193). Oxford: Oxford University Press.

Unión Europea (1996). Reglamento (CE) 1257/96 del Consejo sobre la ayuda humanitaria. Diario Oficial de las Comunidades Europeas, L 163.

Unión Europea (2013). Decisión 1313/2013/UE relativo al Mecanismo de Protección Civil de la Unión. Unión Europea (2014). Reglamento (UE) 375 / 2014 del Parlamento Europeo y del Consejo, por el que se crea el Cuerpo Voluntario Europeo de Ayuda Humanitaria, Iniciativa Voluntarios de Ayuda de la Ue. Diario Oficial de la Unión Europea (DOEU L 122/1)

van Elsuwege, P. (2010). Eu External Action after the Collapse of the Pillar Structure: In Search of a New
Balance between Delimitation and Consistency. Common Market Law Review, 47 (4), 987-1019. van Elsuwege, P. y Orbie, J. (2014), The Eu's Humanitarian Aid Policy after Lisbon: Implications of a New Treaty Basis. En Govaere, I. y Poli, S. (eds.). EU Management of Global Emergencies: Legal Framework for Combating Threats and Crises (pp. 20-45). Leiden: Brill.

Versluys, H. (2008a). Depoliticising and europeanising humanitarian aid: Success or failure? Perspectives on European Politics and Society, 9 (2), 208-224. Versluys, H. (2008b). European humanitarian aid: Lifesaver or political tool? En Orbie, J. (ed.). Europe's Global Role. External Policies of the European Union (pp. 91-116). Aldershot: Ashgate Werleigh, G. y Brouwer, E. J. (2011). How to Help Haiti Help Itself. European Voice. 